\title{
Penetration and lubrication evaluation of vegetable oil with nanographite particles for broaching process
}

\author{
Ming XU, Xin YU, Jing NI* \\ School of Mechanical Engineering, Hangzhou Dianzi University, Hangzhou 310018, China \\ Received: 12 February 2020 / Revised: 21 Aril 2020 / Accepted: 15 June 2020 \\ (C) The author(s) 2020.
}

\begin{abstract}
With increasing environmental concerns, the substitution of mineral oil-based cutting fluid has become an urgent issue. Using vegetable soybean oil as base fluid, nanofluid cutting fluids (NFCFs) were prepared by adding different weight concentrations of nanographite particles (NGPs), and their penetration and lubrication performances were studied. A novel simulated tool-chip slit with micrometersized geometry was manufactured to evaluate and quantify the penetration rate of the NFCFs by image analysis approach. Moreover, a large number of comparative experiments on the closed-type broaching machine were carried out to compare the performance of the proposed NFCFs and a commercial cutting fluid in terms of cutting force, workpiece surface roughness, and metal chip. It is found that there is an optimal NGP concentration in NFCF for practical cutting applications. When the concentration of NGP is $0.4 \mathrm{wt} \%$, the broaching process lubrication exhibits an ideal mixed lubricate state, resulting in minimal friction resistance, and thus, both the cutting force and chip curling angle reach their corresponding best values. Moreover, the proposed NGP-based vegetable-oil cutting fluid exhibits excellent environmentfriendliness and low-cost consumption in the minimal quantity lubrication (MQL) method; this demonstrates its potential for replacing the traditional broaching cutting fluid.
\end{abstract}

Keywords: cutting fluid; vegetable oil; nano-graphite particle; penetration; broaching

\section{Introduction}

Cutting fluids are usually indispensable to modern cutting processes, wherein the fluid is responsible for lubrication, cooling, chip removal, and other functions [1-3]. In broaching or other cutting applications, the mineral oil-based cutting fluid is largely used because of its acceptable lubrication and cooling effect. However, recent studies have shown that the mineral oil-based cutting fluid could cause great harm to the human body and environment [4-7], which would increase the probability of workers suffering from various diseases or the ecosystem being damaged by an improper discharge of waste cutting fluid. The environmental concerns increasingly highlight the importance of green cutting fluid $[8,9]$. Owing to the non-toxicity and biodegradability of vegetable oil, many researchers investigated the possibility of vegetable oils replacing mineral oils in cutting fluid preparation. Belluco and de Chiffre [10] compared the machining effect of five vegetable oil-based cutting fluids and a commercial cutting fluid in drilling austenitic stainless steel. The experiments showed that the vegetable oil-based cutting fluids effectively reduced the cutting force and prolonged the tool life. Cetin et al. [11] found that vegetable cutting fluid with a high concentration of extreme pressure agents can greatly reduce the cutting force when turning AISI 304 stainless steels. Lawal et al. [12] studied the

* Corresponding author: Jing NI, E-mail: nj2000@hdu.edu.cn 
performance of vegetable cutting fluid in the turning process and found that the coconut oil-based cutting fluid improved the surface roughness and significantly reduced the tool wear.

The nanofluid cutting fluid (NFCF) is also a prospective alternative to traditional cutting fluid [13-15]. The base of nanofluid is usually water or oil, and nanoparticles with good lubrication or heat transfer characteristics are added. Thus, the nanofluid combines the fluidity of the base fluid with the lubricity or heat dissipation of nanoparticles $[8,16]$. Amrita et al. [17] used nano-graphite as an additive to make nanofluid, thereby reducing the cutting force and tool wear and improving the surface roughness compared with the traditional cutting fluid. Pashmforoush and Delir Bagherinia [18] prepared a water-based NFCF with nanocopper particles and demonstrated its advantage of offering reduced surface roughness and longer grinding wheel life using minimal quantity lubrication (MQL) technology. Sharma et al. [19] used alumina and graphene as additives and found that the mixed NFCF has the effect of reducing wear, friction coefficient, and nodal temperature in turning. Wang et al. [20] presented a nanofluid with $\mathrm{MoS}_{2}$ and $\mathrm{Al}_{2} \mathrm{O}_{3}$ for grinding, which could decrease wheel wear and surface roughness considerably. Wickramasinghe et al. [21] found that the coconut oil-based fluid could prolong tool life and decrease cutting temperature. Li et al. [22] investigated the graphene nanoparticles-based vegetable cutting fluid to improve the milling performances of TC4 alloy.

Broaching is a kind of metal cutting process with high machining efficiency and surface quality, which is widely chosen for machining some important parts in aerospace, automobile, or vessel industries [23]. The characteristics of closed machining and heavy load determine the difference between broaching and other machining processes. Firstly, the closed machining of broaching makes it difficult for cutting fluid to be injected into the cutting area, unlike turning or milling [24]. The cutting teeth of the broaching tool are deeply buried in the workpiece. Regardless of using traditional pouring or emerging MQL, the cutting fluid cannot be directly sent to the tool and chip contact area but is suspended on tool teeth as cutting droplets and subsequently passively brought into the processing area by the relative movement of the workpiece and tool. Secondly, the broaching force is usually very large; consequently, long-term broaching under dry or semi-dry conditions could greatly reduce the tool life. Although the MQL technology has been applied to many processing fields [25-27], the pouring of mineral oil-based cutting fluid with high viscosity is still adopted in broaching, at the cost of harm to the human body and environment.

It is crucial to find an environment-friendly cutting fluid for broaching. Using vegetable soybean oil as base fluid, NFCFs were prepared by adding different weight concentrations of the nano-graphite particle (NGP). Moreover, the supply method of NFCF should be MQL, which reduces the cutting fluid consumption. However, MQL broaching requires strong permeability of NFCF. The NFCF can penetrate the tool-chip slit in closed broaching, to obtain a good lubrication performance and reduce the broaching force. In this study, a novel simulated tool-chip slit with micrometer-sized geometry was built to evaluate and quantify the penetration rate of the NFCFs by image analysis approach. Moreover, a large number of comparative experiments on the closed-type broaching machine were carried out to compare the performance of the proposed NFCFs and a commercial broaching fluid.

\section{Experimental}

\subsection{Preparation of NFCF}

The base oil is an important component of NFCFs, which has a direct impact on penetration and lubrication performance. As one of the most conventional vegetable oils, soybean oil can be purchased directly from the market and is inexpensive. An environment-friendly NFCF was prepared using soybean oil as the base oil and NGPs as additives. Graphite is often used as a lubricant in the form of graphite microparticles evenly distributed in water, oil, or other liquids [28]. The microparticles existed as extremely fine particles (30 nm diameter) in this study. It can penetrate the tool-chip interface and play a favorable lubrication 
role. By adding a certain amount of dodecylbenzene sulfonate to the proposed NFCF, soybean oil and additive NGP could be separated easily without causing harm to the environment.

The experiment groups comprised NFCFs with different NGP weight percentages, as listed in Table 1. Each NFCF was named according to the following convention: NGP plus the number that represented the weight concentration of the NGP.

In order to simplify the preparation process of NFCFs, a two-step method was chosen. The first step was to stir the mixture of soybean oil and NGPs at $300 \mathrm{r} / \mathrm{min}$ for $45 \mathrm{~min}$ using a magnetic stirrer. The second step was to stir the mixture for $20 \mathrm{~min}$ at $20 \mathrm{kHz}$ frequency using an $80 \mathrm{~W}$ ultrasonic device. After the two-step preparation, the welldispersed NFCFs could be obtained (Fig. 1). Moreover, a commercial broaching oil (CBO) M1083 produced by Sinopec Lubricant Company was used as a control group.

\subsection{Experimental system}

\subsubsection{Penetration system}

The penetration characteristic refers to the ability of the cutting fluid to enter the tool-workpiece-

Table 1 Compositions of six cutting fluids.

\begin{tabular}{ccc}
\hline Cutting fluids & $\begin{array}{c}\text { Soybean } \\
\text { oil (wt\%) }\end{array}$ & $\begin{array}{c}\text { Nanographite } \\
\text { particle (wt\%) }\end{array}$ \\
\hline NGP-00(Pure soybean oil, PSO) & 100 & 0 \\
NGP-02 & 99.8 & 0.2 \\
NGP-04 & 99.6 & 0.4 \\
NGP-06 & 99.4 & 0.6 \\
NGP-08 & 99.2 & 0.8 \\
CBO & - & - \\
\hline
\end{tabular}

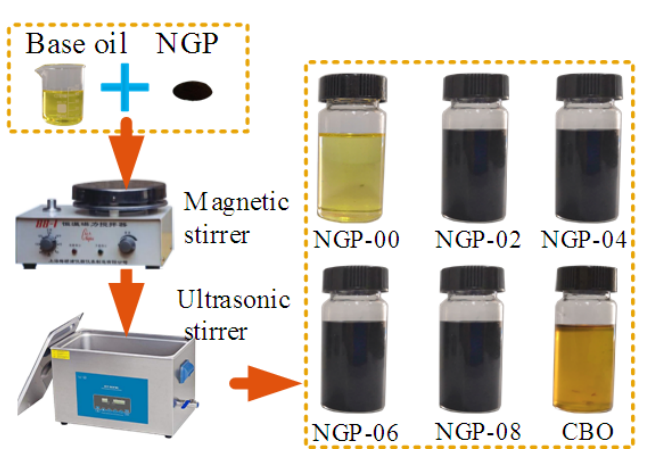

Fig. 1 Preparation of NFCFs. chip interface for lubrication and cooling. When the cutting fluid is sprayed by pouring, there is usually no need to consider penetration because the cutting fluid is supplied in a sufficient amount. However, in MQL mode, the penetration of cutting fluid is indispensable. The penetration of cutting fluid to the tool-chip zone is essentially a wettingspreading process of cutting droplets in a slit formed by two solid surfaces: One solid surface represents the tool and the other is the chip. This slit width is of cross-scale, from millimeters to micrometers, and even nanometers.

In order to investigate and quantitatively study the penetration of NFCF droplets in the tool-chip contact zone, a simulated experimental device was designed. As shown in Fig. 2, the device consists of three parts: a simulated slit, a droplet supply device, and an observation system. The slit portion is mainly composed of a simulated tool-chip slit and a fixing device. This part is used to simulate the shape of the contact area between the rake face and chip during the cutting process. The droplet supply device mainly comprises a servo propulsion device and a microliter syringe. Moreover, the device is clamped and fixed using fixtures and bases. This part is used to squeeze a certain amount of droplet to be measured into the simulated slit. The observation system includes a high-speed camera and penetration image analyzing software; this part is used to record and analyze the entire process of droplet penetration.

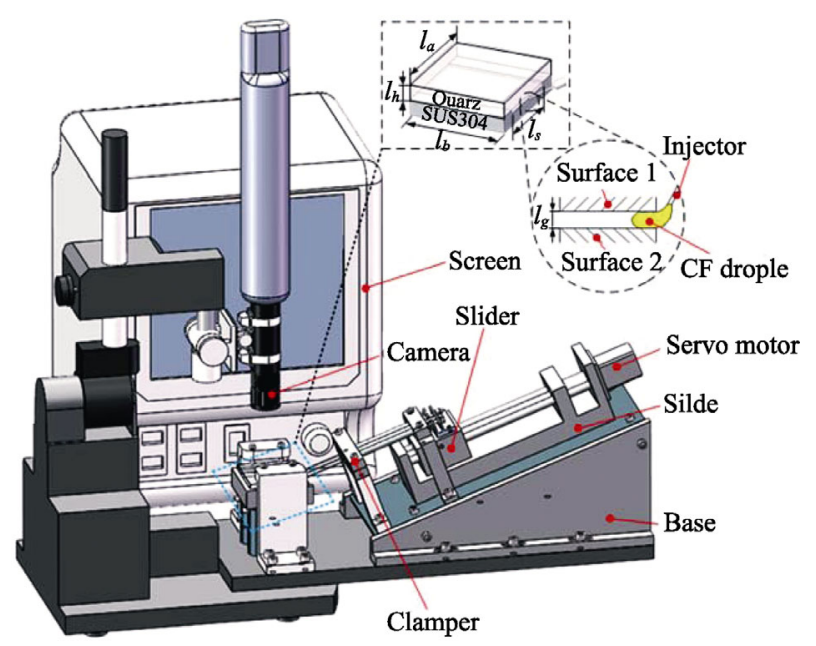

Fig. 2 Penetrativity measurement of cutting fluid in simulated tool-chip slit. 
The simulated slit is composed of upper quartz (JGS3, $R a=1 / 4 \lambda$ ) Plate 1 , and lower metal (ASTM $304, R a=1.6 \mu \mathrm{m}$ ) Plate 2. For plate 1 and plate 2, length $l_{\mathrm{a}}=60 \mathrm{~mm}$, width $l_{\mathrm{b}}=60 \mathrm{~mm}$, and thickness $l_{\mathrm{h}}=10 \mathrm{~mm}$. Moreover, there is a micro concave plane on the surface of the lower plate with length $l_{\mathrm{S}}=40 \mathrm{~mm}$ and groove depth $l_{\mathrm{g}}=200 \mu \mathrm{m}$. Thus, the upper and lower plates were brought together by a pressing device, and a $200 \mu \mathrm{m}$ simulated slit was produced. Cutting fluid droplets of $0.5 \mu \mathrm{L}$ is delivered to the slit opening with a supplying system that is designed with a microsyringe (stainless steel needle, $10 \mu \mathrm{L}$ syringe) and a servo-driven slider (max stroke $100 \mathrm{~mm}$, position accuracy $0.01 \mathrm{~mm}$, and max speed $100 \mathrm{~mm} / \mathrm{s}$ ). The observation device includes a high-speed camera (Keyence VH-Z50L, set 2000 fps, magnification 50, and resolution $640 \times 480$ ) and a monitor computer (Keyence VW-9000). These configurations are designed to monitor the transient process of droplet penetration in the simulated slit.

By observing the droplet spreading process, it is found that the area occupied by the NFCF droplets is much darker than the unoccupied area, as shown in Fig. 3. Therefore, this study uses image processing to evaluate the spreading process, which does not need to add tracer particles into NFCF droplets. The penetration image processing is divided into four phases: background removal, noise removal, binary morphology operations, and area summation.

The penetration area can be extracted by the image analyzing method. Then, by multiplying the

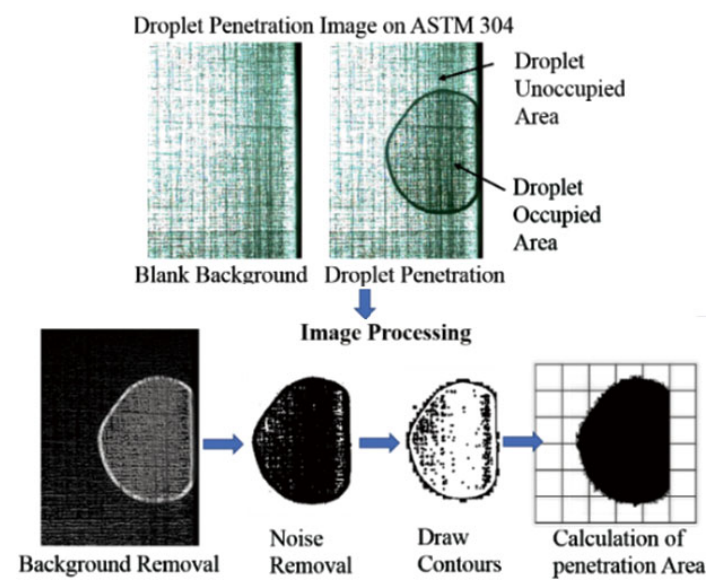

Fig. 3 Image analyzing method of the penetration process. penetration area by slit height, the volume $V(t)$ at which the droplet has penetrated the slit can be calculated.

\subsubsection{Broaching system}

1) Broaching machine

As shown in Fig. 4, broaching experiments were conducted on an internal broaching machine (Changer LG61Ya-800). The broaching tool is held by a clamper and driven by the main cylinder moving from right to left, thereby completing the cutting process. The main cylinder has a piston diameter of $80 \mathrm{~mm}$, a piston rod diameter of $45 \mathrm{~mm}$, and a stroke of $800 \mathrm{~mm}$. The rated oil pressure and flow of the system are $6 \mathrm{MPa}$ and $100 \mathrm{~L} / \mathrm{min}$, respectively. The rated speed of the cutting process is $80 \mathrm{~mm} / \mathrm{s}$. The maximum force of broaching is $20 \mathrm{kN}$.

2) Data acquisition

As shown in Fig. 4, the experimental data acquisition system includes a displacement sensor, two pressure sensors, and a data acquisition instrument. The displacement sensor was used to evaluate the smoothness of the cutting process with the cutting speed signal obtained by differential operation of displacement. Owing to the broaching structure, it is difficult to mount the strain gauge directly on the cutter teeth to measure the cutting force, an indirect measurement solution needs to be found. In this study, the broaching force was measured by the pressures in the cylinder having two chambers. The two pressure sensors were installed on the oil inlet and outlet of the main cylinder, for detecting the corresponding pressures $p_{1}$ and $p_{2}$, respectively. The model of the two oil pressure sensors is SYPG5205 with a scale range of $0-10 \mathrm{MPa}$ and sensibility of $2 \mathrm{mV} / \mathrm{V}$. The flow areas of the rod chamber and rodless chambers are $A_{1}$ and $A_{2}$, respectively. The broaching load $F$ can be calculated by the following formula:

$$
F=p_{1} A_{1}-p_{2} A_{2}
$$

The signals of displacement and pressure sensors were collected by the data acquisition instrument (DAQ). The model of the DAQ is YouTai uT3408FRS with sampling frequency $1,024 \mathrm{~Hz}$ and resolution 24 bit. Moreover, a surface roughness tester SJ- 


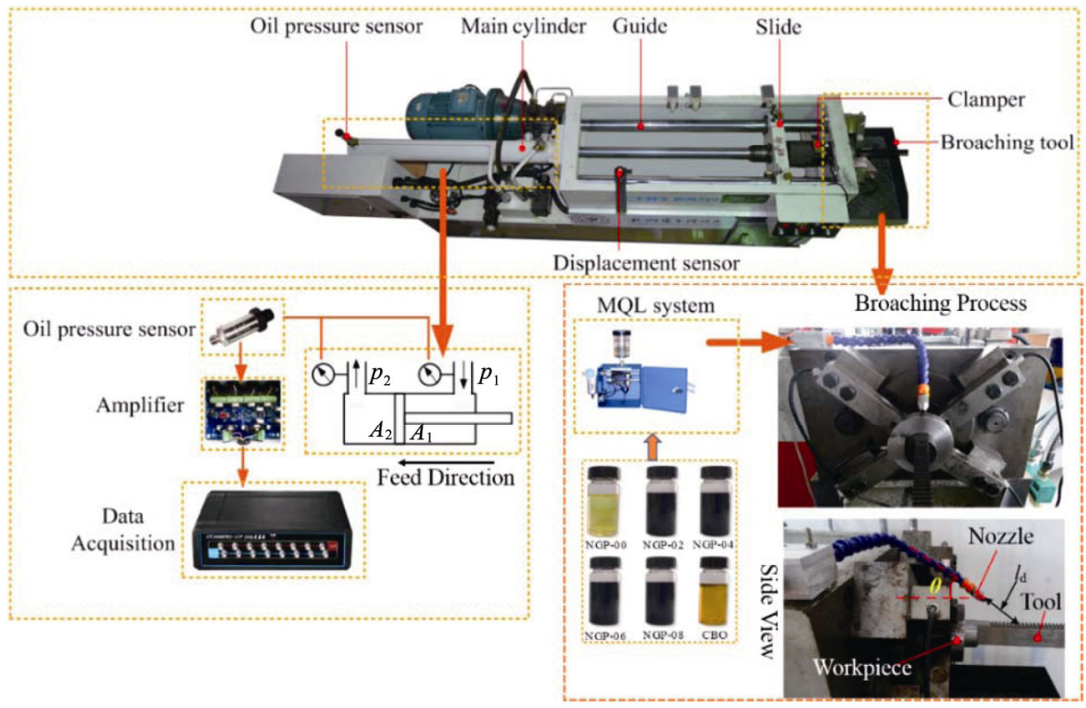

Fig. 4 Broaching experimental system.

210 was used to measure the cut workpiece. The microscope Keyence VW-9000 was used to observe the shape of cutting chips.

3) Broaching tool

As shown in Fig. 5, the broaching tool used in the experiment is made of AISI T1. For this tool, its length $L=600 \mathrm{~mm}$, width $b=16 \mathrm{~mm}$, front height $h_{1}=34.94 \mathrm{~mm}$, and rear height $h_{\mathrm{M}}=36.73 \mathrm{~mm}$. In total, there are 49 teeth on one tool. The increment heights $\delta_{i}$ are listed in Table 2. According to the increment height $\delta_{i}$ of each tooth, the total tool teeth can be divided into three parts: the rough cutting zone $\left(1-n_{\mathrm{R}}\right)$, semi-fine cutting zone $\left(n_{\mathrm{R}}+\right.$ $\left.1-n_{\mathrm{S}}\right)$, and fine cutting zone $\left(n_{\mathrm{S}}+1-n_{\mathrm{M}}\right) \cdot n_{\mathrm{R}}, n_{\mathrm{S}}$, and $n_{\mathrm{M}}$ are the number of rough, semi-fine, and fine cutting teeth, respectively. According to Table 2, $n_{\mathrm{R}}=40, n_{\mathrm{S}}=45$, and $n_{\mathrm{M}}=49$. Using the teeth from rough to semi-fine cutting zone, the workpiece is machined

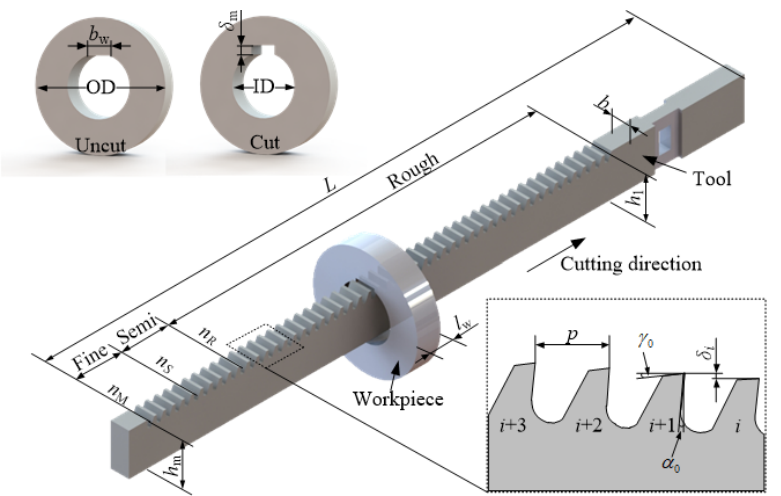

Fig. 5 Broaching tool and workpiece. to the required depth, while teeth on the fine cutting zone ensure the surface quality of the machined surface. For the single tooth, its rake angle $\gamma_{0}=12^{\circ}$, clearance angle $\alpha_{0}=6^{\circ}$, and pitch $p=6 \mathrm{~mm}$.

Table 2 Increment height of each tooth.

\begin{tabular}{ccc||ccc}
\hline No.i & $\delta_{i}(\mathrm{~mm})$ & Zone & No.i & $\delta_{i}(\mathrm{~mm})$ & Zone \\
\hline 1 & - & Rough & 26 & 0.04 & Rough \\
2 & 0.04 & Rough & 27 & 0.04 & Rough \\
3 & 0.04 & Rough & 28 & 0.04 & Rough \\
4 & 0.04 & Rough & 29 & 0.04 & Rough \\
5 & 0.04 & Rough & 30 & 0.04 & Rough \\
6 & 0.04 & Rough & 31 & 0.04 & Rough \\
7 & 0.04 & Rough & 32 & 0.04 & Rough \\
8 & 0.04 & Rough & 33 & 0.04 & Rough \\
9 & 0.04 & Rough & 34 & 0.04 & Rough \\
10 & 0.04 & Rough & 35 & 0.04 & Rough \\
11 & 0.04 & Rough & 36 & 0.04 & Rough \\
12 & 0.04 & Rough & 37 & 0.04 & Rough \\
13 & 0.04 & Rough & 38 & 0.04 & Rough \\
14 & 0.04 & Rough & 39 & 0.04 & Rough \\
15 & 0.04 & Rough & 40 & 0.04 & Rough \\
16 & 0.04 & Rough & 41 & 0.03 & Semi \\
17 & 0.04 & Rough & 42 & 0.03 & Semi \\
18 & 0.04 & Rough & 43 & 0.02 & Semi \\
19 & 0.04 & Rough & 44 & 0.02 & Semi \\
20 & 0.04 & Rough & 45 & 0.01 & Semi \\
21 & 0.04 & Rough & 46 & 0.01 & Fine \\
22 & 0.04 & Rough & 47 & 0 & Fine \\
23 & 0.04 & Rough & 48 & 0 & Fine \\
24 & 0.04 & Rough & 49 & 0 & Fine \\
25 & 0.04 & Rough & - & - & - \\
\hline & & & & &
\end{tabular}




\section{4) Workpiece}

The uncut and cut configuration of the ring workpiece is shown in Fig. 5. Its material is AISI 1045. Machining planes are generated on the inner surface of the ring workpiece. For the workpiece, its outer diameter $O D=90 \mathrm{~mm}$, inner diameter $I D=$ $43 \mathrm{~mm}$, thickness $l_{\mathrm{w}}=20 \mathrm{~mm}$, width $b_{\mathrm{w}}=16 \mathrm{~mm}$, and keyway deep $\delta_{\mathrm{m}}=1.83 \mathrm{~mm}$ after processing.

5) Cutting fluid supply system

The MQL device Accu-lube 02A3STD-LLMB (Fig. 4) was used as the cutting fluid supply device in this experiment. This MQL device can mix and atomize cutting fluid with compressed air and spray the cutting fluid into the slit in the tool, workpiece, and chip. The flow rate of cutting fluid was set to $0.95 \mathrm{~mL} / \mathrm{min}$. An atomization nozzle was used with a working gas pressure 7 bar. A ramp angle $(\theta)$ of $15^{\circ}$ and distance $\left(l_{\mathrm{d}}\right)$ of $50 \mathrm{~mm}$ was used in the atomization nozzle to attain the best lubrication and cooling condition.

\section{Results}

\subsection{Physical characteristics of cutting fluids}

The viscosity and wetting angle are the basic characteristics of cutting fluids. These characteristics represent their internal resistance, adhesion, and spreading performance and have a major influence on the lubrication and cooling conditions. Figure 6 shows the viscosity and wetting angle comparisons. The viscosities were tested with SYD-256I viscometer

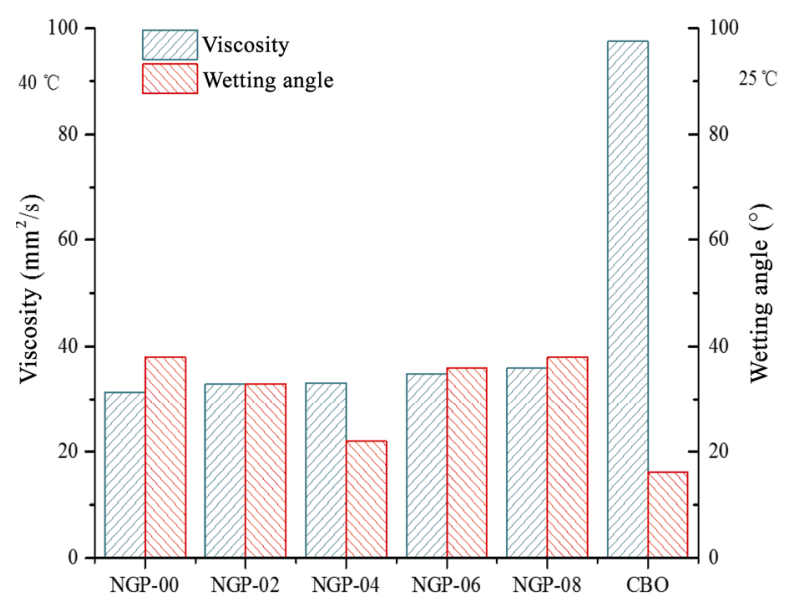

Fig. 6 Viscosity and wetting angles of cutting fluids. at $40{ }^{\circ} \mathrm{C}$ and $1 \mathrm{~atm}$, and the wetting angles were calculated by measurements using the micrographs photographed by KEYENCE VW-9000 high-speed microscope.

For the NFCFs, the higher the NGP weight concentration, the higher viscosity of the cutting fluid. Since the maximum NGP weight concentration is only $0.8 \%$, the viscosity of the five NFCFs (NGP00NGP08) has little difference. The viscosity of CBO M1083 is very large and almost reaches $100 \mathrm{~mm}^{2} / \mathrm{s}$. This is because CBO M1083 is designed for broaching heavy loads and requires a large viscosity of cutting fluid to meet the lubrication demand. The wetting angles of the five prepared NFCFs first decrease and then increase with the increase in NGP concentration. Moreover, the minimum value of the wetting angle is observed at $0.4 \mathrm{wt} \%$ mass fraction of NGP, namely for NGP-04. The waterbased emulsified cutting fluid M1083 has the smallest wetting angle.

\subsection{Penetration experiments}

Penetrativity of cutting fluids performs a major role in lubrication on the limited surface of the workpiece, tool, and chip since all cutting parameters were unchanged during the broaching process. Meanwhile, the atomization application of cutting fluids with nozzle reduces the amount of cutting fluid supplied per unit of time, and the penetrativity of cutting fluids would become increasingly important.

With the proposed penetration measurement device, volumes of penetrated droplets over time were recorded as the evaluation index for penetration processes of six types of cutting fluid.

At the moment of cutting fluids penetrating the simulated slit, a certain volume has penetrated under the action of capillary force. Owing to the extremely short penetration times, these instants were difficult to be measured. To compare the penetration speeds of the six cutting fluids, a time zero was set at which volumes of penetrated cutting fluids were approximately equal, as shown in Fig. 7.

The penetrated volumes of the six cutting fluids at $135 \mathrm{~ms}$ are $92 \mathrm{~nL}, 111 \mathrm{~nL}, 138 \mathrm{~nL}, 84 \mathrm{~nL}, 67 \mathrm{~nL}$, and $20 \mathrm{~nL}$, respectively, where the volumes over the entire $135 \mathrm{~ms}$ are equal to the volumes at $135 \mathrm{~ms}$ 


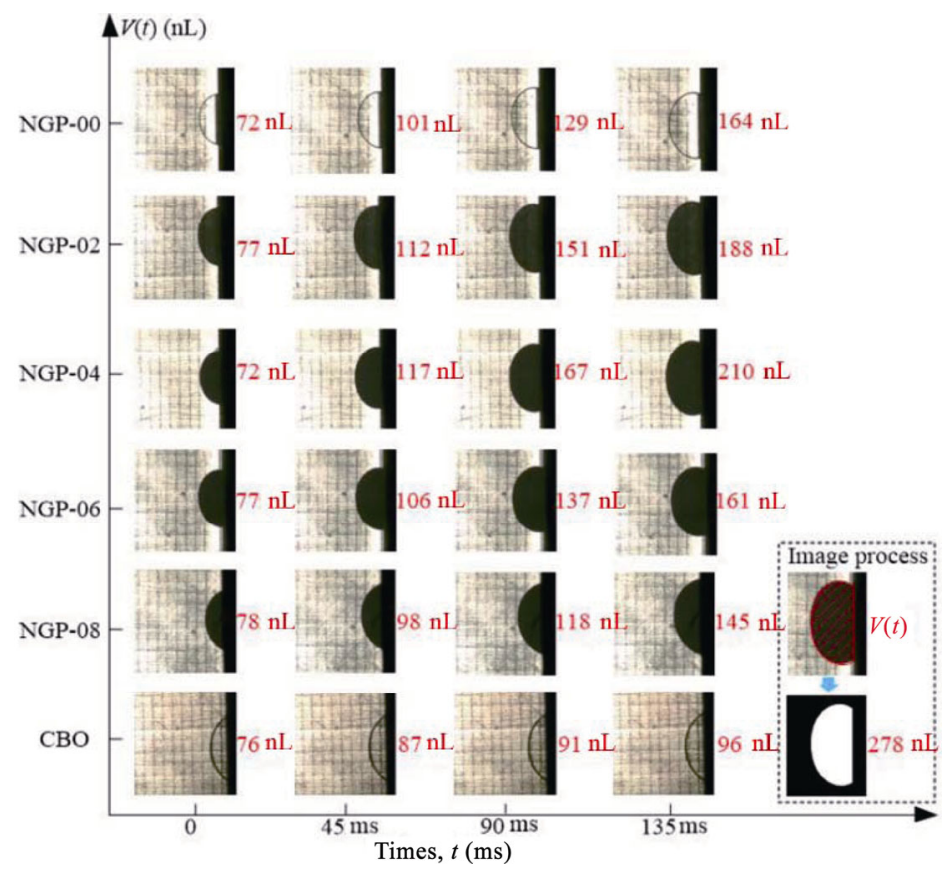

Fig. 7 Penetration process of six cutting fluids.

minus the volumes at $0 \mathrm{~ms}$. The maximum penetration speed of $138 \mathrm{~nL}$ at $135 \mathrm{~ms}$ was found for NGP-04.

The penetration speed is quantified in this study, which is defined as the volume of penetrated cutting fluid per unit time. As shown in Fig. 8, it can be seen that as the NGP concentrations increase, the penetration speeds of the six cutting fluids increase first and then gradually decrease. Regardless of the penetration time, the maximum penetration speed was recorded for the NGP concentration of $0.4 \%$. Owing to the high viscosity, it is difficult for CBO

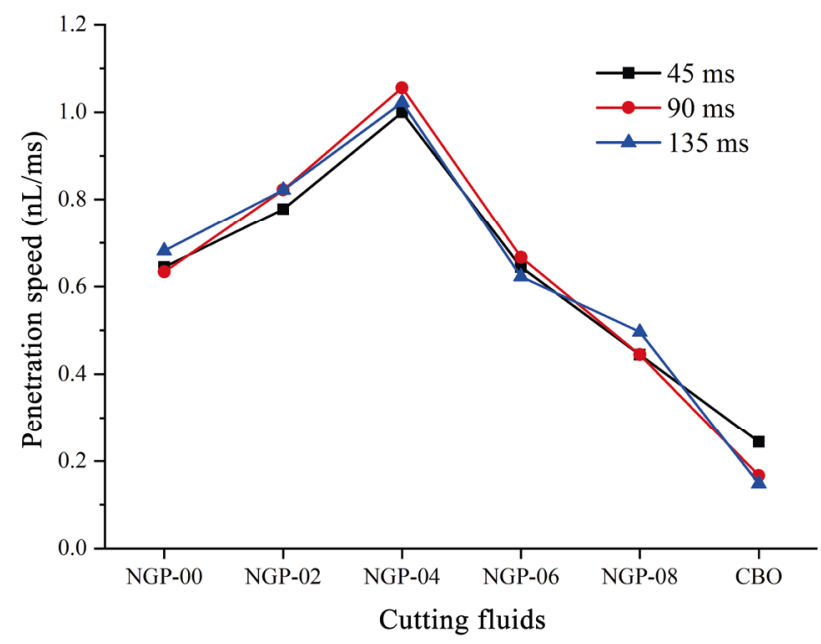

Fig. 8 Quantified penetration speeds of six cutting fluids. to penetrate the slit, thus rendering its penetration speed the slowest among the six cutting fluids.

\subsection{Cutting force}

The cutting force is a critical indicator to evaluate the cutting fluid. Under the working condition with a cutting speed of $80 \mathrm{~mm} / \mathrm{s}$, the pressure data measured by the oil pressure sensors were used to calculate the cutting forces for six cutting fluids according to Eq. (1). As shown in Fig. 9, it can be seen that the force peaks at the early stages of each broaching process are uncertain. At the beginning of broaching, the broach teeth and the workpiece are not in contact yet. The factors affecting the broaching force at this moment of instantaneous teeth-workpiece contact are very complicated, such as the crystal structure of the workpiece to be processed and the hardness of the tooth contact zone. From the first to fourth teeth, as the tool teeth continue to cut the workpiece, the increased cutting area increases the broaching force. In the subsequent cutting teeth of $5-45$, the stable cutting stage emerges.

Since the width of workpiece, $l_{\mathrm{W}}=20 \mathrm{~mm}$, and the pitch of teeth $p=6 \mathrm{~mm}$, i.e., $l_{\mathrm{w}}>3 p$, the teeth numbers engaging in cutting varies between 3 and 


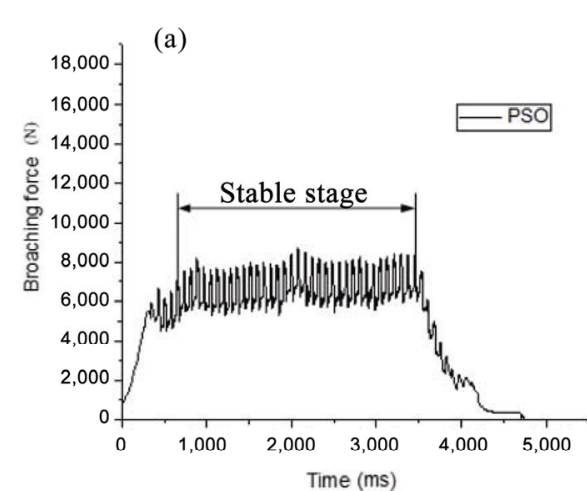

(d)

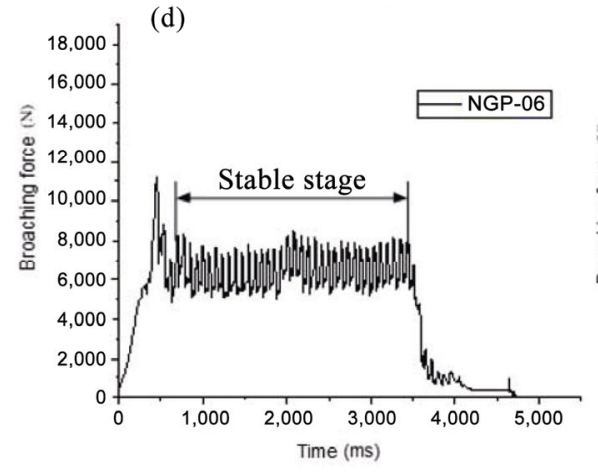

(b)

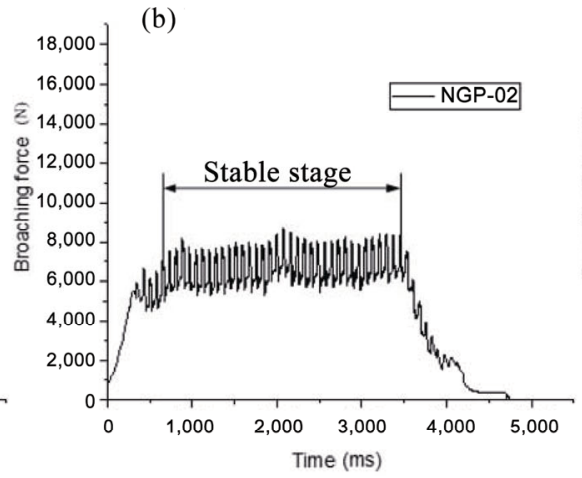

(e)

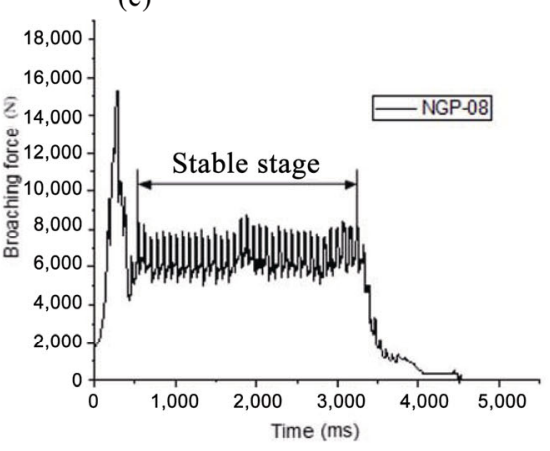

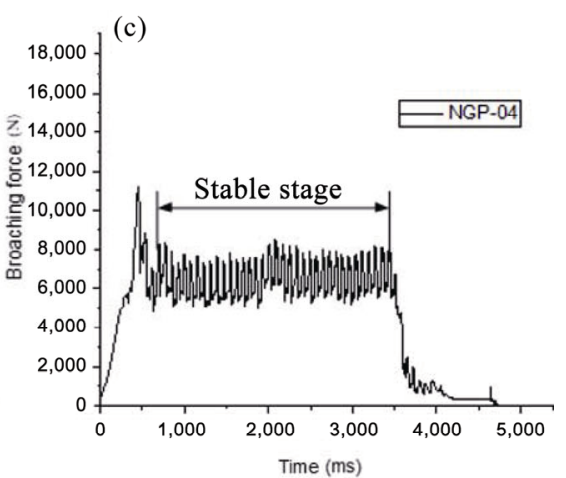

(f)

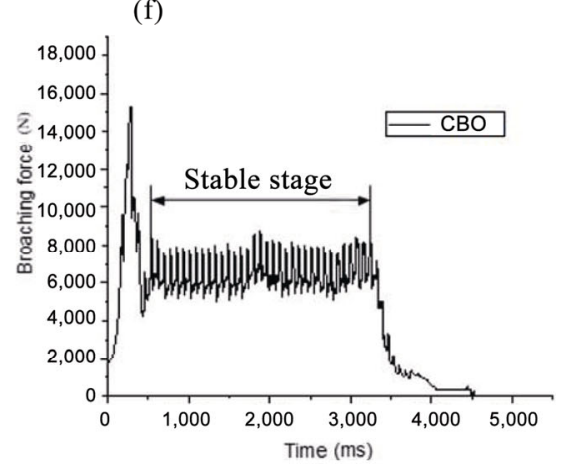

Fig. 9 Cutting forces of different cutting fluids.

4 in the broaching process. Therefore, the broaching force is high during 4-teeth cutting and low during 3-teeth cutting. Several high and low values of broaching force are recorded in one pass of the broaching. Then, the mean high value (mean value of 4-teeth cutting force) and the mean low value (mean value of 3-teeth cutting force) are calculated.

As shown in Fig.10, the mean high value and mean low value of broaching force decrease and then increase with the increase in the concentration of NGP in cutting fluids. The error bars are mainly owing to the hydraulic pressure sensors in the broaching machine. Note that when the mass fraction of NGP is $0.4 \mathrm{wt} \%$, namely for NGP-04, 7.4 and $5.6 \mathrm{kN}$ are recorded as the mean high and low levels of the broaching force, respectively. Compared with the absence of NGP-00 (NGP $0.0 \mathrm{wt} \%$ ) and NGP-08 (NGP $0.8 \mathrm{wt} \%$ ), there are reductions of approximately $400 \mathrm{~N}$ (mean high value), $500 \mathrm{~N}$ (mean low value), $220 \mathrm{~N}$ (mean high value), and $250 \mathrm{~N}$ (mean low value), respectively. The same result is obtained when comparing NGP-04 with $\mathrm{CBO}$, i.e., the broaching forces are reduced by
$200 \mathrm{~N}$ (mean high value) and $200 \mathrm{~N}$ (mean low value). Variation trends of broaching force with the increase in NGP concentration of soybean oil in cutting fluids are consistent with the variation trends of penetration speed. Lower broaching force implies better lubrication and cooling performance, thus offering a longer tool life.

This variation trend of broaching force is also evidenced by the curling angles of the chip. As illustrated in Fig. 11, variation trends of broaching

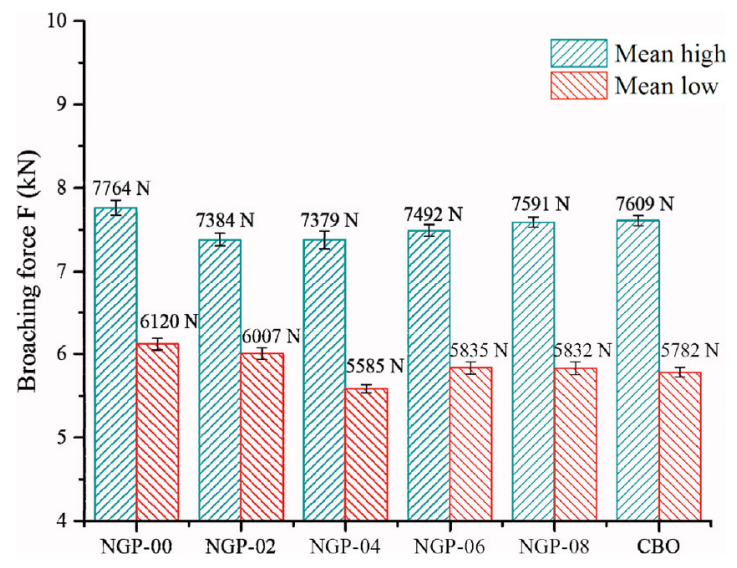

Fig. 10 Broaching force with different cutting fluids. 


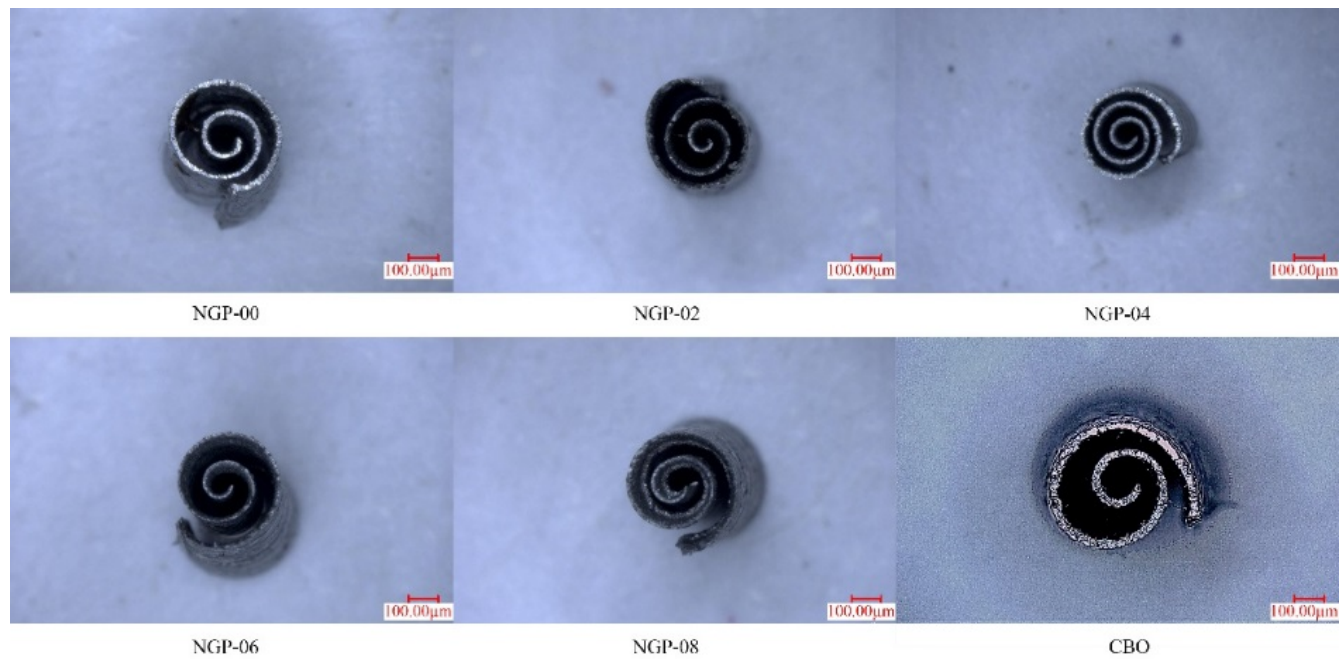

Fig. 11 Curling chips with six cutting fluids.

forces and curling angles are consistent with the increase in NGP concentration. Moreover, NGP-04 exhibits the maximum value of the curling angle (more than $3 \times 360^{\circ}$ ). Lager curling angle results in the easier formation of the chip and also offers better lubrication and cooling performance.

\subsection{Surface roughness}

The surface roughness of the machined workpiece is another indicator for exhibiting the cutting fluid performance. For the six cutting fluids, three broaching experiments were conducted for each cutting fluid, and then, the surface roughness $R a$ of each machined workpiece was measured three times. Their average values are calculated and plotted in Fig. 12. The roughness error is determined by comprehensively considering the accuracy of roughness detector SJ-210 and the roughness measurement method. For each cutting fluid, the error bar is defined as \pm $0.25 \mu \mathrm{m}$. The main factor affecting the surface roughness is the wetting angle of the cutting fluid. For NGP cutting fluids (NGP02-NGP08), the surface roughness also decreases first and then increases with the increase in NGP concentration, which is consistent with the measurement results of wetting angles shown in Fig. 6. The results from Fig. 12 shows that there is no obvious difference in the processing quality between the vegetable oils (NGP00-NGP08) and commercial broaching oil $(\mathrm{CBO})$. This indicates that the proposed cutting fluid has the potential to replace $\mathrm{CBO}$ with respect to the surface quality of the machined workpiece.

\section{Discussion}

\subsection{Influence of NGP on penetration}

First, we discuss the influence of NGP on the penetrativity of cutting fluid droplets, since the penetration characteristics of cutting fluid droplets are closely related to the lubrication performance. The cutting fluid supply is sufficient for pouring in the traditional broaching process, and there is usually no need to consider the penetration process. However, in MQL mode, the penetration of cutting fluid is crucial.

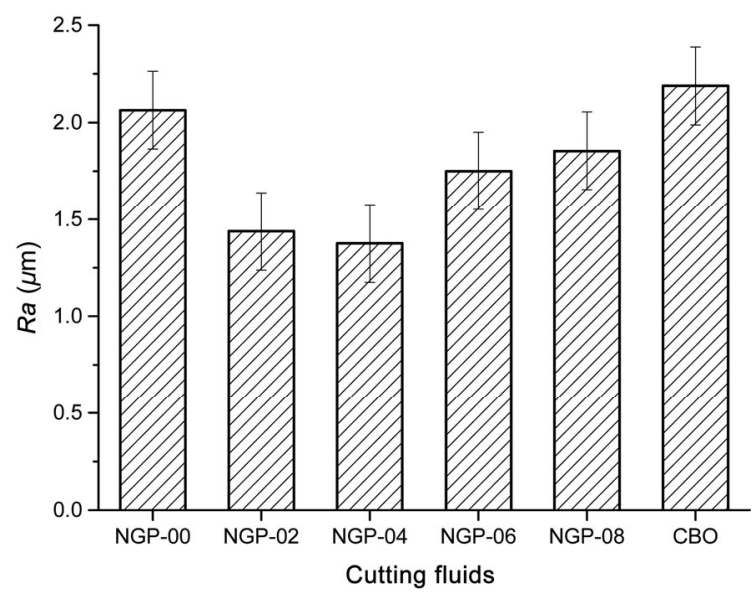

Fig. 12 Roughness of cut workpieces with six cutting fluids. 
As shown in Figs. 7, 8, and 10, wetting angles and their variations, which are representative of the penetration characteristics $[1,3,9]$, are sensitive to the concentration of NGP. The mechanism for this phenomenon is shown in Fig. 13.

When the concentration of NGP is lower than $0.4 \mathrm{wt} \%$ (NGP-04), as shown in Fig. 14(a), the graphite nanoparticles are well distributed in the soybean oil after ultrasonic agitation. In this case, the suspended NGP would be attracted to the metal surface with high surface energy and develops a tendency to flatten the droplet. Hence, with the increase in NGP concentration, the decrease in wetting angle occurs, as shown in Fig. 6. A decrease in the wetting angle indicates that the spreadability of cutting droplets improves.

However, when the concentration of NGP is higher than $0.4 \mathrm{wt} \%$ (NGP-04), another phenomenon occurs. As shown in Fig. 14(b), excessive NGPs converge on the droplet surface and produce a "self-assembly" effect because of the attraction between particles. As shown in Fig. 14(c), the NGPs converge on the interface of vegetable oil and air. This process increases the surface tension of cutting fluid droplets, thereby balancing or even overcoming the attraction of solid surface molecules toward NGPs. In this case, with the increase in NGP concentration, the wetting angle becomes increasingly larger, as shown in Fig. 13(b), which is also proved as shown in Fig. 6.

\subsection{Influence of NGP on lubrication}

Second, we discuss the influence of NGPs on lubrication, and it is crucial since the lubrication of cutting fluid is directly related to the broaching force and tool life [4, 14, 20,27]. After the droplets sprayed by MQL enter the cutting zone, viscosity is one of the main factors that affect lubrication performance [27]. The flow of high-viscosity cutting fluid is restricted by the viscous force, and thus, the fluid has poor flowability, which results in difficulty in penetrating the tool-chip slit. This is the reason for the poorest penetration of $\mathrm{CBO}$ M1083 with the biggest viscosity among the six cutting fluids, although the wetting angle of $\mathrm{CBO}$ is minimal, as shown in Fig. 6. However, in the case

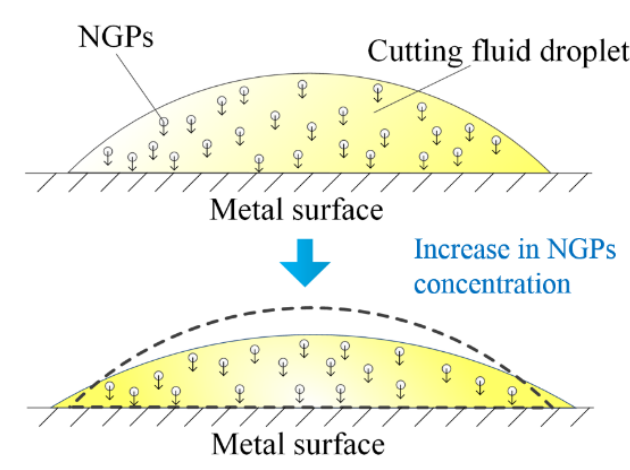

(a) NGP $\leqslant 0.4 w t \%$

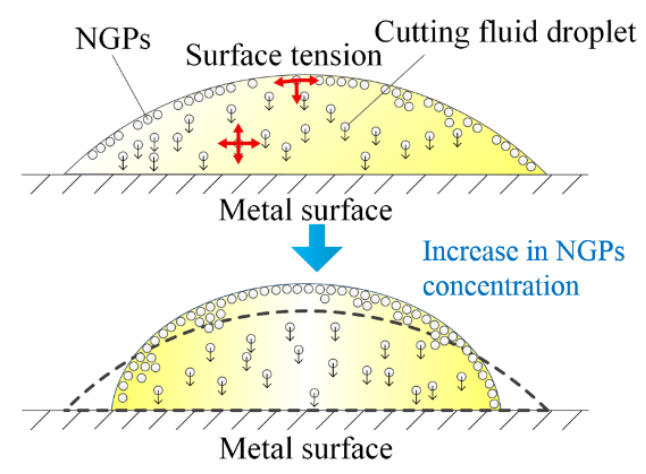

(b) NGP $>0.4 \mathrm{wt} \%$

Fig. 13 Mechanism of wetting angle variation.

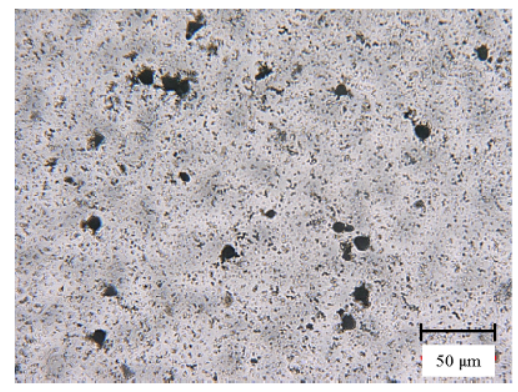

(a) Well-distributed NGPs

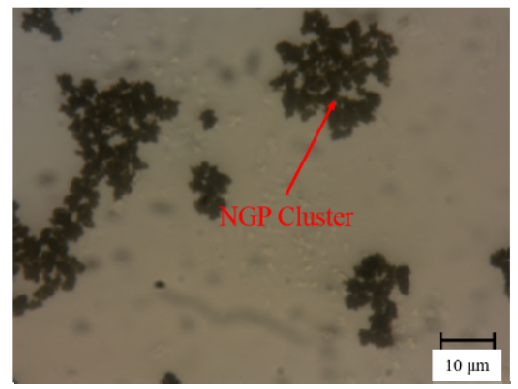

(b) NGP Cluster

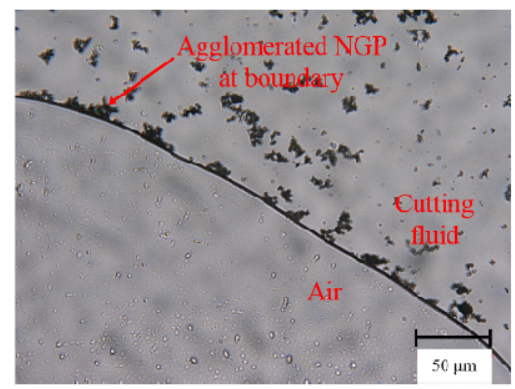

(c) Agglomerated NGP at boundary

Fig. 14 Microscopic observations of cutting fluid. 
of pouring, the cutting fluid with a higher viscosity tends to have a better lubrication effect, because it is easier to form a lubricating film without considering the insufficiency of cutting fluid [3,26].

As shown in Figs .9 and 10, broaching forces and their variations are important representatives of the lubrication performance of cutting fluids and are sensitive to the concentration of NGPs. Therefore, NGPs can change the lubrication performance of cutting fluid. The influence mechanism can be described by the distribution and dispersion of the base oil and NGP between tool and workpiece, as shown in Fig. 15.

In the case of dry cutting, as shown in Fig. 15(a), the friction between the rake face and the chip is dry. At this time, the micro convex peaks shear extrusion each other at the interface between the tool and workpiece, thus generating a large cutting force and a huge amount of heat. Owing to the heavy load, dry cutting is not suitable for broaching. After spraying the vegetable oil, as shown in Fig. 15(b), a lubricant film would be formed at the tool-workpiece interface. The energy dispersive spectrometer (EDS) analysis confirmed this conclusion [29]. When friction occurs between the broach teeth and the workpiece surface, the liquid film is subjected to a large load, resulting in a low possibility of maintaining liquid lubrication, and almost all of them are in the boundary lubrication state.

When the concentration of NGP is lower than $0.4 \mathrm{wt} \%$ (NGP-04), as shown in Figs. 15(b) and 15(c), the lubrication state between tool and chip

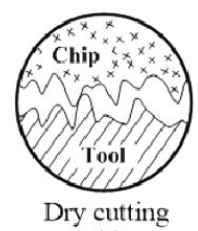

(a)

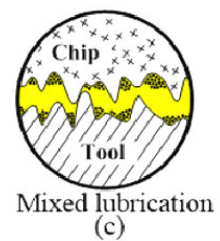

(c)

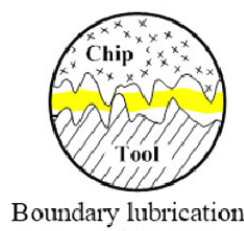

(b)

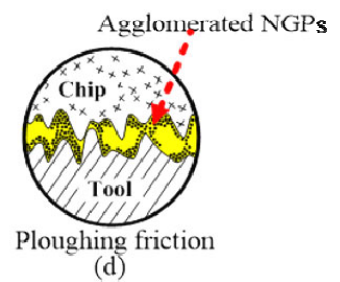

(d)
Fig. 15 Role of nanoparticles under different conditions. converts from boundary lubrication to mixed lubrication. The graphite has a hexagonal crystal structure, strong bearing capacity, and a small friction coefficient. The NGPs in vegetable oil is well distributed as shown in Fig. 14(a). Since NGP has the characteristics of high strength and high hardness, it maintains the particle form under a large load, fills the gap between the tool and chip, and plays the role of a "bearing" to reduce the friction coefficient of the broaching area. With the increase in the concentration of NGPs $(0.2 \mathrm{wt} \%$ to $0.4 \mathrm{wt} \%)$, the mean low broaching force reduces to $422 \mathrm{~N}$, and the chip curl angle increases to $110^{\circ}$, as shown in Figs.10 and 11 .

When the concentration of NGP is larger than $0.4 \mathrm{wt} \%$, as shown in Fig. 15(d), the ploughing friction gradually appears and intensifies. As the NGP concentration increases, the chances of NGPs colliding with each other to form larger graphite particles increase, and eventually, the agglomeration phenomenon occurs, as shown in Figs. 14(b) and 14(c). The agglomerated NGPs increase the friction coefficient between the tool and the chip. With the increase in the concentration of NGPs $(0.4 \mathrm{wt} \%-0.8 \mathrm{wt} \%)$, the mean high and mean low broaching forces increase to 210 and $247 \mathrm{~N}$, respectively, and the chip curl angle decreases to $105^{\circ}$, as shown in Figs. 10 and 11.

Therefore, there is an optimal NGP concentration in cutting fluid for a practical cutting application. When the concentration of NGP is equal to a certain value, the lubrication exhibits an ideal mixed lubricate state, resulting in minimal friction resistance. However, the NGP concentration should not be allowed to exceed the exact concentration; this can be determined by repeated cutting experiments.

The vegetable oil-based NFCF prepared in this study has good biodegradability. Firstly, the soybean oil, as the base liquid in cutting fluid, is a typical renewable resource with good biodegradability. Secondly, the NGPs can be well dispersed in soybean oil without precipitation for a long time and thus will not cause damage to the injection system of cutting fluid. Thirdly, by adding a certain amount of dodecylbenzene sulfonate to the proposed cutting fluid, oil, and additive NGPs can be separated easily without causing harm to the environment. This is because the activator molecules of dodecylbenzene 
sulfonate can connect and bind graphite molecules with each other, resulting in condensation and precipitation of graphite.

Moreover, the commercial broaching oil is usually added by pouring, and the cutting fluid consumption reaches $5,000 \mathrm{~mL} / \mathrm{min}$. Because of the excellent lubrication performance of green NFCF, better cutting performance can be achieved by using the MQL method, and the cutting fluid consumption needs to be only $0.950 \mathrm{~mL} / \mathrm{min}$. Compared with the traditional commercial broaching oil sprayed by pouring, the optimal NFCF prepared in this study and injected using MQL has very promising application prospects.

\section{Conclusions}

1) Penetrativity of cutting fluids has a major role in lubrication on the limited surface of the tool, workpiece, and chip. The maximum penetration speed of $138 \mathrm{~nL}$ at $135 \mathrm{~ms}$ was recorded for NGP04 . Variation trends of penetration speed with the increase in the concentration of soybean oil in cutting fluids are consistent with the variation trends of broaching force.

2) The influence mechanism of NGP concentration on lubrication is divided into three stages according to NGP concentration: boundary lubrication state, mixed lubrication state, and ploughing friction state. There is an optimal NGP concentration in cutting fluid for practical cutting applications. When the concentration of NGP is $0.4 \mathrm{wt} \%$ (NGP-04), the lubrication exhibits an ideal mixed lubricate state, resulting in minimal friction resistance.

3) The NGPs can be easily separated from the biodegradable vegetable soybean oil, which exhibits excellent environment-friendliness and low-cost consumption. Using MQL to inject the optimal NFCF is a very promising alternative to the traditional method.

\section{Acknowledgements}

This study is supported by the National Natural Science Foundation of China (Grant Nos. 51775153 and 51975171).

Open Access This article is licensed under a Creative Commons Attribution 4.0 International License, which permits use, sharing, adaptation, distribution and reproduction in any medium or format, as long as you give appropriate credit to the original author(s) and the source, provide a link to the Creative Commons licence, and indicate if changes were made.

The images or other third party material in this article are included in the article's Creative Commons licence, unless indicated otherwise in a credit line to the material. If material is not included in the article's Creative Commons licence and your intended use is not permitted by statutory regulation or exceeds the permitted use, you will need to obtain permission directly from the copyright holder.

To view a copy of this licence, visit http://creativecommons.org/licenses/by/4.0/.

\section{References}

[1] Gajrani K K, Suvin P S, Kailas S V, Sankar M R. Hard machining performance of indigenously developed green cutting fluid using flood cooling and minimum quantity cutting fluid. J Clean Prod 206: 108-123 (2019)

[2] Shashidhara Y M, Jayaram S R. Vegetable oils as a potential cutting fluid-An evolution. Tribol Int 43(5-6): 1073-1081 (2010)

[3] Ni J, Feng K, He L H, Liu X F, Meng Z. Assessment of water-based cutting fluids with green additives in broaching. Friction 8(6): 1051-1062 (2020)

[4] Debnath S, Reddy M M, Yi Q S. Environmental friendly cutting fluids and cooling techniques in machining: A review. J Clean Prod 83: 33-47 (2014)

[5] Chetan, Ghosh S, Venkateswara Rao P. Application of sustainable techniques in metal cutting for enhanced machinability: A review. J Clean Prod 100: 17-34 (2015)

[6] Katna R, Singh K, Agrawal N, Jain S. Green manufacturing-Performance of a biodegradable cutting fluid. Mater Manuf Process 32(13): 1522-1527 (2017)

[7] Madanchi N, Leiden A, Winter M, Asbach C, Lindermann J, Herrmann C, Thiede S. Cutting fluid emissions in grinding processes: Influence of process parameters on particle size and mass concentration. Int J Adv Manuf Technol 101(1-4): 773-783 (2019) 
[8] Padmini R, Vamsi Krishna P, Krishna Mohana Rao G. Effectiveness of vegetable oil based nanofluids as potential cutting fluids in turning AISI 1040 steel. Tribol Int 94: 490-501 (2016)

[9] Yuan S M, Hou X B, Wang L, Chen B C. Experimental investigation on the compatibility of nanoparticles with vegetable oils for nanofluid minimum quantity lubrication machining. Tribol Lett 66(3): 106 (2018)

[10] Belluco W, de Chiffre L. Performance evaluation of vegetable-based oils in drilling austenitic stainless steel. J Mater Process Technol 148(2): 171-176 (2004)

[11] Cetin M H, Ozcelik B, Kuram E, Demirbas E. Evaluation of vegetable based cutting fluids with extreme pressure and cutting parameters in turning of AISI 3041 by Taguchi method. J Clean Prod 19(17-18): 2049-2056 (2011)

[12] Lawal S A, Choudhury I A, Nukman Y. Developments in the formulation and application of vegetable oil-based metalworking fluids in turning process. Int J Adv Manuf Technol 67(5-8): 1765-1776 (2013)

[13] Khandekar S, Sankar M R, Agnihotri V, Ramkumar J. Nano-cutting fluid for enhancement of metal cutting performance. Mater Manuf Process 27(9): 963-967 (2012)

[14] Sharma A K, Tiwari A K, Dixit A R. Effects of Minimum Quantity Lubrication (MQL) in machining processes using conventional and nanofluid based cutting fluids: A comprehensive review. J Clean Prod 127: 1-18 (2016)

[15] Gupta M K, Jamil M, Wang X J, Song Q H, Liu Z Q, Mia M, Hegab H, Khan A M, Collado A G, Pruncu C I, et al. Performance evaluation of vegetable oil-based nano-cutting fluids in environmentally friendly machining of inconel-800 alloy. Materials 12(17): 2792 (2019)

[16] Revuru R S, Zhang J Z, Posinasetti N R, Kidd T. Optimization of titanium alloys turning operation in varied cutting fluid conditions with multiple machining performance characteristics. Int J Adv Manuf Technol 95(1-4): 1451-1463 (2018)

[17] Amrita M, Srikant R R, Sitaramaraju A V. Performance evaluation of nanographite-based cutting fluid in machining process. Mater Manuf Process 29(5): 600-605 (2014)

[18] Pashmforoush F, Delir Bagherinia R. Influence of water-based copper nanofluid on wheel loading and surface roughness during grinding of Inconel 738 superalloy. J. Clean Prod 178: 363-372 (2018)

[19] Sharma A K, Tiwari A K, Dixit A R, Singh R K, Singh $M$. Novel uses of alumina/graphene hybrid nanoparticle additives for improved tribological properties of lubricant in turning operation. Tribol Int 119: 99-111 (2018)

[20] Wang Y G, Li C H, Zhang Y B, Yang M, Li B K, Dong L, Wang J. Processing characteristics of vegetable oil-based nanofluid MQL for grinding different workpiece materials. Int J Precis Eng Manuf Green Technol 5(2): 327-339 (2018)

[21] Wickramasinghe K C, Perera G I P, Herath H M C M. Formulation and performance evaluation of a novel coconut oil-based metalworking fluid. Mater Manuf Process 32(9): 1026-1033 (2017)

[22] Li M, Yu T B, Yang L, Zhang R Y, Wang W C, Wang W $\mathrm{S}$. Parameter optimization during minimum quantity lubrication milling of TC4 alloy with graphenedispersed vegetable-oil-based cutting fluid. $J$ Clean Prod 209: 1508-1522 (2019)

[23] Hosseini A. On the quality and integrity of broached surfaces. Int J Adv Manuf Technol 102(1-4): 95-103 (2019)

[24] Hwang J. Direct observation of fluid action at the chip-tool interface in machining. Int J Precis Eng Manuf 15(10): 2041-2049 (2014)

[25] Behera B C, Chetan, Setti D, Ghosh S, Rao P V. Spreadability studies of metal working fluids on tool surface and its impact on minimum amount cooling and lubrication turning. J Mater Process Technol 244: 1-16 (2017)

[26] Sen B, Mia M, Krolczyk G M, Mandal U K, Mondal S P. Eco-friendly cutting fluids in minimum quantity lubrication assisted machining: A review on the perception of sustainable manufacturing. Int J Precis Eng Manuf Green Technol 8: 249-280 (2021)

[27] Said Z, Gupta M, Hegab H, Arora N, Khan A M, Jamil $\mathrm{M}$, Bellos E. A comprehensive review on minimum quantity lubrication (MQL) in machining processes using nano-cutting fluids. Int $J$ Adv Manuf Technol 105(5-6): 2057-2086 (2019)

[28] Wu P, Chen X C, Zhang C H, Zhang J P, Luo J B, Zhang $\mathrm{J}$ Y. Modified graphene as novel lubricating additive with high dispersion stability in oil. Friction 9(1): 143 154 (2021)

[29] Zahoor S, Ameen F, Abdul-Kader W, Stagner J. Environmentally conscious machining of Inconel 718: Surface roughness, tool wear, and material removal rate assessment. Int J Adv Manuf Technol 106(1-2): $303-$ $313(2020)$ 


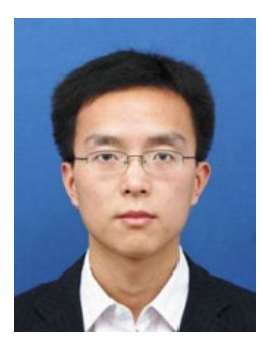

Ming XU. He received his Ph.D. degree in mechatronics from Zhejiang University, China, 2009. He joined the School of Mechanical Engineering at Hangzhou Dianzi

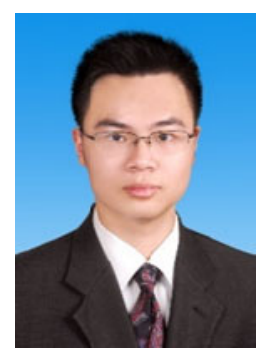

Xin YU. He received his bachelor degree in mechanical engineering in 2016 from Shanghai University, China. He obtained his M.S.

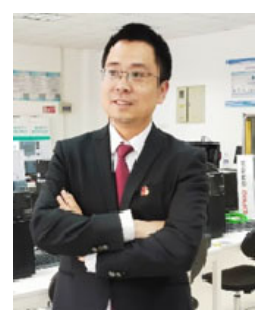

Jing NI. He is a professor and dean of the Mechanical Engineering School at Hangzhou Dianzi University. He attained his Ph.D. and
University in 2009. His current position is as an associate professor. His research areas cover the soft robotics and mechatronics.

degree in mechanical engineering at Hangzhou Dianzi University, China, 2020. His research interest is green cutting fluid.

master degrees from Zhejiang University. His research interests are green cutting fluid, high hardness surface, and functional microstructure. 